\title{
Oral rehabilitation for a geriatric population -A voluntary experience in Ukraine report
}

\author{
Alex Mersel ${ }^{1}$, Yaroslav Zablotsky ${ }^{2}$, Myron Uhryn ${ }^{3}$ \\ ${ }^{1}$ Department Community Dentistry, Faculty of Dental Medicine, Hebrew University, Hadassah, Jerusalem \\ ${ }^{2}$ Ukrainian Dental Implantology Association, Kyiv, Ukraine \\ ${ }^{3}$ Ukrainan Association of Private Practice Dentits, Kyiv, Ukraine \\ Email: mersal@netvision.net.il
}

Received 27 March 2012; revised 23 April 2012; accepted 3 May 2012

\begin{abstract}
Despite the outstanding progress in dentistry, there are still a great number of edentulous patients worldwide, what's more, the dentists are not willing to inform the patients about their handicapped condition. Elderly people do not complain about this a lot, and also unfortunately the general public and government authorities do not concerne too much about gerodontic issues. The elderly people has suffered greatly from this. Dental implant is one way to figure this out. The Ukrainian Dental Implant Association has initiated a professional voluntary project entitled: “Quality of Life for our Parents". This geriatric welfare program offers free implant and Prosthetic rehabilitation for the Elderly edentulous patients.
\end{abstract}

Keywords: Gerodontic; Edentulous; Implant Overdentures

\section{INTRODUCTION}

It is well known that the elderly population is significantly and constantly increasing [1]. They are diverse and heterogeneous with different medical conditions, behavioral characteristics and specific dental needs. The epidemiological surveys point out that approximately $95 \%$ of them live in the community, $17 \%$ have some mobility limitations, only 5\% of them are homebound. In total, over $70 \%$ are able to travel to a dentist [2]. Despite the number of edentulous patients is decreasing, a large majority of these patients need a complete denture restoration [3]. Concerning the lower jaw, the mandibular denture is presenting a great challenge for the dental practitioner [4]. The medical issues for the compromised systemic diseases are very common and are an obstacle for an Implant therapy [5]. In addition, the amount of fees necessarily to realize an implant supported lower denture is too high for the majority of the aged people [6]. Considering the retirement pension in Ukraine is about
100 euros and the price of the reconstruction about 2000 euros, it is clear that retired people cannot afford such a procedure. In general, the elderly population is not well informed about implant treatment and therefore many of them refused to undergo oral surgery. Therefore in Ukraine a group of dental Implant leaders decided to launch a voluntary charitable action in order to provide a "quality of life for their parents". To reach these goals a special program based on the collaboration between oral surgeon and prosthodontist was programmed. The aim of this report is to launch an appeal to the profession in order to mobilize voluntary actions for the geriatric population.

\section{METHODS AND MATERIALS}

The number of patients treated was, 212:108 males and 104 females. The age repartition was from 63 the youngest and 92 the oldest (Table 1). Before the treatment the patients received the necessary examinations like Orthopantogram and blood analysis. They were carefully screened and examines by hospital specialist.All the patients were hospitalized for five days: 2 days before the intervention and 3 days after. Following the program the project was conducted in eight main Ukrainian cities (Table 2). In every city a very strict organization was necessary. The dentists never work together before and never operated in hosting Hospital prior the project. All the participating oral surgeons were distributed in teams. Each team was constituted by four members: a surgeon, a prosthodontist and two assistant's In addition an active Logistic center was created. Each participant was informed about the working area as well the location of his patient at any time. Each surgeon received in due time the patient's chart and an evaluated radiographs, and did not operated more than three patients a day.

Despite that different convictions and opinions were frequent, all the staff was following a single and simple protocol; up to four parallel implants were inserted in the intra-mental space of the edentulous mandible. Concerning 
Table 1. Geographical distribution of the patients.

\begin{tabular}{ccccccccccc}
\hline & Males & Females & Youngest & Oldest & Dental condition Surgeons involved Prosthetists & Dental units & Implants & Dentures \\
\hline Simferopol & 5 & 0 & 77 & 81 & Edentulous & 2 & 2 & 2 & 33 & 8 \\
Kyiv & 33 & 23 & 65 & 92 & Edentulous & 50 & 50 & 30 & 289 & 72 \\
Odesa & 13 & 13 & 65 & 88 & Edentulous & 13 & 12 & 12 & 104 & 26 \\
Lviv & 11 & 17 & 70 & 88 & Edentulous & 13 & 13 & 13 & 112 & 28 \\
Sevastopol & 16 & 4 & 70 & 86 & Edentulous & 20 & 19 & 20 & 81 & 20 \\
Dnipropetrovsk & 17 & 15 & 69 & 88 & Edentulous & 31 & 30 & 15 & 128 & 32 \\
Ivano-Frankivsk & 11 & 11 & 63 & 90 & Edentulous & 15 & 14 & 15 & 88 & 22 \\
Cherkasy & 2 & 2 & 81 & 91 & Edentulous & 4 & 4 & 4 & 16 & 4 \\
Total & 108 & 85 & 560 & 704 & - & 148 & 144 & 111 & 851 & 212 \\
\hline
\end{tabular}

Table 2. Medicaments intake of the patients.

\begin{tabular}{ccc}
\hline & Number of patients & Percentage \\
\hline Etamsylate & 87 & 46 \\
Dexalgin & 128 & 68 \\
Fentanyl & 56 & 30 \\
Promedolum & 32 & 17 \\
Atropini Sulfas & 49 & 26 \\
Dexametazon & 42 & 22 \\
Propofol & 55 & 29 \\
Diazepam & 74 & 39 \\
Benzohexonium & 21 & 11 \\
Kordaron & 20 & 10.5 \\
MgSO $_{4} 25 \%$ & 76 & 40 \\
\hline
\end{tabular}

the surgical Units they offered more easy working facilities than the classic Dentist clinic chair. After surgery the patients were escorted to the prosthetic Units were the prosthodontist inserted prefabricated immediate overdentures. Just in case a Dental Labor was present for a technical support. The entire project was realized under the support of the Ministry of Health and the Ministry of Defense within the facilities of military and local communal hospital.

\section{RESULTS}

In total were involved 148 Surgeons and 144 Prosthodontists working on 111 Dental Units. The number of Implants was 851 and 212 lower complete dentures were delivered. It is planed such kind of action for the years 2011 and 2012 in Kyiv. The final treatments were afterwards examined on a Prosthetic level by means of den- tures basis adequacy, retention, occlusion and esthetics [7]. In regard of these criteria $86 \%$ of the prosthetic devices were found acceptable. A number of positive targets were achieved:

- First a relative important number of elderly were treated in a short delay.

- Second, the close Collaboration between the Oral Surgeons and the Prosthodontists after a common treatment planning for each patient.

- Third, the cooperation if necessary of a prosthetic laboratory located in the facilities.

- Fourth, overall the publicity by the media on this action, giving this way a focus on the Geriatric Population problems.

On a psychological point of view, the Practitioners that were very cautious at first, turned in real satisfaction and enjoying their work. This satisfaction was not only because their professional pride but mainly because a sense of social responsibility [8].

\section{DISCUSSION}

It is obvious that the role of a voluntary action is not to replace national welfare programs. But such kind of program can drive the attention of the Public and the authorities to the existing problems and the implement of required standards.

Since dentists are seldom involved in charity or social projects, it is important to develop an opportunity participating in a so essential Community program [9].

The support of the Partners in the Dental Industry was an important contribution for this action.

Actually this project is supported in other countries: Warsaw Poland, Tbilisi Georgia, Almaty Kazakhstan, and Moscow Russia.

These actions are of course limited concerning the extent and the number of patients treated. There are numerous frail patients house-bounded that need Mobile 
Units care. In the same way actually the majority of the elderly need more complex treatments involving, Periodontal, Conservative, and Restorative care.

\section{CONCLUSION}

The dental profession is not only concerned by the interests of its members and Continuing Education activities. Dental Associations should take part in the community and give to the practitioner an opportunity to share experiences, learn specific skills and acquire new ideas and social solidarity.

\section{REFERENCES}

[1] Bourgeois, D., Nihtila, A. and Mersel, A. (1998) Prevalence of caries and edentulousness among 65 - 74 years old in Europe. Bulletin of the World Health Organization, 76, 413-417.

[2] Canadian Dental Association (2009) Optimal health for frail older adults. Best Practices along the Continuum of Care, Ottawa, 6-9.
[3] Ivanhoe, J.R., et al. (2002) Treating the modern complete denture patient: A review of literature. Journal of Prosthetic Dentistry, 88, 631-635. doi:10.1067/mpr.2002.130147

[4] Turkyilmaz, I., et al. (2010) Should edentulous patients be constrained to removable complete dentures? The use of dental implants to improve the quality of life for edentulous patients. Gerodontology, 27, 3-10. doi:10.1111/j.1741-2358.2009.00294.x

[5] Scully, C. and Ettinger, R.L. (2007) The influence of systemic diseases on oral health in older adults. Journal of the American Dental Association, 138, 7S-14S.

[6] Macek, M.D., et al. (2004) Dental visits among older US adults; the roles of dental status and costs. Journal of the American Dental Association, 135, 1154-1162.

[7] Beck, C.B. (1993) A survey of the dissatisfied Denture patient. European Journal of Prosthodontics and Restorative Dentistry, 2, 73-78.

[8] Carney, K.K., et al. (2011) Dental volunteering efforts. Journal of the American Dental Association, 39, 353-356.

[9] Pietrokovski, H. and Zini, A. (2006) The Yad Sarah geriatric clinic, a different model. Gerodontology, 23, 237241. doi:10.1111/j.1741-2358.2006.00121.x 